\title{
Abnormalities in Intracellular Calcium Regulation and Contractile Function in Myocardium from Dogs with Pacing-induced Heart Failure
}

\author{
Cynthia L. Perreault, Richard P. Shannon, Kazuo Komamura, Stephen F. Vatner, and James P. Morgan \\ Charles A. Dana Research Institute and the Harvard-Thorndike Laboratory of Beth Israel Hospital, Department \\ of Medicine (Cardiovascular Division), Harvard Medical School, Boston, Massachusetts 02215; \\ and the New England Regional Primate Research Center, Southborough, Massachusetts 01772
}

\begin{abstract}
$24 \mathrm{~d}$ of rapid ventricular pacing induced dilated cardiomyopathy with both systolic and diastolic dysfunction in conscious, chronically instrumented dogs. We studied mechanical properties and intracellular calcium $\left(\mathrm{Ca}_{1}^{2+}\right)$ transients of trabeculae carneae isolated from 15 control dogs $(n=32)$ and 11 dogs with pacing-induced cardiac failure $(n=26)$. Muscles were stretched to maximum length at $30^{\circ} \mathrm{C}$ and stimulated at 0.33 Hz; a subset ( $n=17$ control, $n=17$ myopathic) was loaded with the $\left[\mathrm{Ca}^{2+}\right]_{\mathrm{b}}$ indicator aequorin. Peak tension was depressed in the myopathic muscles, even in the presence of maximally effective (i.e., $16 \mathrm{mM}$ ) $\left[\mathrm{Ca}^{2+}\right]$ in the perfusate. However, peak $\left[\mathrm{Ca}^{2+}\right]_{\text {i }}$ was similar $\left(0.80 \pm 0.13\right.$ vs. $0.71 \pm 0.05 \mu \mathrm{M} ;\left[\mathrm{Ca}^{2+}\right]_{0}=2.5$ $\mathrm{mM}$ ), suggesting that a decrease in $\mathrm{Ca}_{i}^{2+}$ availability was not responsible for the decreased contractility. The time for decline from the peak of the $\mathrm{Ca}_{\mathrm{i}}^{2+}$ transient was prolonged in the myopathic group, which correlated with prolongation of isometric contraction and relaxation. However, similar end-diastolic $\left[\mathrm{Ca}^{2+}\right]_{i}$ was achieved in both groups $(0.29 \pm 0.05$ vs. $0.31 \pm 0.02$ $\mu \mathrm{M}$ ), indicating that $\mathrm{Ca}_{\mathrm{i}}^{2+}$ homeostasis can be maintained in myopathic hearts. The inotropic response of the myopathic muscles to milrinone was depressed compared with the controls. However, when cAMP production was stimulated by pretreatment with forskolin, the response of the myopathic muscles to milrinone was improved. Our findings provide direct evidence that abnormal $\left[\mathrm{Ca}^{2+}\right]_{\mathrm{i}}$ handling is an important cause of contractile dysfunction in dogs with pacing-induced heart failure and suggest that deficient production of CAMP may be an important cause of these changes in excitation-contraction coupling. (J. Clin. Invest. 1992. 89:932-938.) Key words: aequorin • cardiomyopathic dogs • intracellular calcium handling • pacing-induced cardiac failure
\end{abstract}

\section{Introduction}

Cardiac hypertrophy and failure produce well-documented changes in myocardial structure and contractile function. Previous studies have presented evidence that implicates abnor-

Address reprint requests to Dr. Morgan, Cardiovascular Division, Beth Israel Hospital, 330 Brookline Avenue, Boston, MA 02215.

Received for publication 25 July 1991 and in revised form 18 September 1991.

1. Abbreviations used in this paper: $\mathrm{LV}$, left ventricular; $\mathrm{RV}$, right ventricular.

J. Clin. Invest.

(C) The American Society for Clinical Investigation, Inc. 0021-9738/92/03/0932/07 \$2.00

Volume 89, March 1992, 932-938 malities in intracellular calcium $\left(\mathrm{Ca}_{\mathrm{i}}^{2+}\right)^{1}$ handling as a major factor contributing to both systolic and diastolic dysfunction (for review, see reference 1). Although many animal models of pressure-overload hypertrophy and myocardial failure have been studied, none have documented the same pathophysiological changes as observed in human myocardium. A finding unique to myopathic human myocardium is that the $\mathrm{Ca}_{i}^{2+}$ transient recorded with aequorin or Indo- 1 is, under some circumstances, composed of two distinct components that appear to reflect both sarcoplasmic reticular and sarcolemmal dysfunction $(2,3)$. Studies in several small animal models of cardiac hypertrophy and failure, including the spontaneously hypertensive rat, pulmonary-artery banded ferret, and congenitally myopathic Syrian hamster, have demonstrated prolonged $\mathrm{Ca}_{i}^{2+}$ transients, but none have yet reproduced the two distinct components (1). In addition, myopathic human myocardium appears to have a unique pharmacological profile suggestive of deficient intracellular production of cAMP, which, in turn, appears to diminish the effectiveness of cAMP-dependent inotropic agents (4).

The purpose of the present study was to investigate myocardial function and $\mathrm{Ca}_{i}^{2+}$ handling in a large animal model of heart failure, which may more closely resemble cardiac failure in humans than do previous studies of small animal models of cardiac hypertrophy and/or failure $(5,6)$. A major advantage of this model is the availability of both in vivo and in vitro measures of contractile function, which permits correlation between hemodynamic manifestations of heart failure and cellular alterations in excitation-contraction coupling.

\section{Methods}

Dilated cardiomyopathy was induced in conscious, chronically instrumented mongrel dogs of either sex by $24 \mathrm{~d}$ of rapid right ventricular (RV) pacing at a rate of 240 beats per minute (bpm) using an externally programmable miniature cardiac pacemaker (model EV4543, Pace Medical, Inc., Waltham, MA). The specific details of the chronic instrumentation have been described elsewhere $(5,6)$. Briefly, dogs were instrumented with left ventricular $(\mathrm{LV})$ miniature pressure transducers (Konigsberg Instruments, Inc., Pasadena, CA), aortic and left atrial catheters, and ultrasonic dimension crystals across the long and short axis of the LV cavity and the LV free wall. A sutureless pacing lead was attached to the RV and all catheters were externalized. A group of sham-operated controls were instrumented similarly. Dogs were monitored daily for clinical signs and symptoms of heart failure. Sham-operated, age- and weight-matched mongrel dogs served as controls. The animals used in this study were maintained in accordance with the National Research Council's Guidelines for the Care and Use of Laboratory Animals and the Standing Committee on Animal Care of Harvard Medical School. Before killing, systemic hemodynamics and myocardial contractile function were assessed in all 15 control dogs and 11 myopathic dogs by measuring LV systolic and end-diastolic pressure and $\mathrm{LV} \mathrm{d} P / \mathrm{d} t$. In a subset of randomly selected control and 
myopathic dogs ( $n=5$ in each group), $\mathrm{RV}$ systolic pressure, end-diastolic pressure, and $\mathrm{RV} \mathrm{d} P / \mathrm{d} t$ were measured in the conscious state using a Millar catheter inserted percutaneously via the saphenous vein. All hemodynamic measurements were taken at the intrinsic heart rate which was $94 \pm 6$ and $126 \pm 7 \mathrm{bpm}$ in the control and myopathic dogs, respectively. At death, LV plus septal weights and RV weights were obtained from all dogs and normalized for preoperative body weight. Hearts were immediately placed in an oxygenated bicarbonate-buffered physiological salt solution of the following composition (mM): $120, \mathrm{NaCl} ; 5.9, \mathrm{KCl} ; 11.5$, glucose; $25, \mathrm{NaHCO}_{3} ; 1.2, \mathrm{NaH}_{2} \mathrm{PO}_{4} \cdot \mathrm{H}_{2} \mathrm{O}$; $1.2, \mathrm{MgCl}_{2} \cdot 6 \mathrm{H}_{2} \mathrm{O} ; 2.5, \mathrm{CaCl}_{2}$. The solution was equilibrated with a gaseous mixture of $95 \% \mathrm{O}_{2} / 5 \% \mathrm{CO}_{2}$ to a pH of 7.4 at $30^{\circ} \mathrm{C}$. 32 control and 26 myopathic RV muscle preparations were dissected from the hearts of 15 control and 11 myopathic dogs under magnification, following fiber orientation. At least one muscle was studied from every heart; but, whenever possible, multiple muscles were obtained. The mean length and width of the entire group of muscle preparations were, respectively, $5.6 \pm 0.9$ and $1.0 \pm 0.08 \mathrm{~mm}$ in the control hearts and $5.6 \pm 0.8$ and $1.1 \pm 0.07 \mathrm{~mm}$ in the myopathic group. The average crosssectional area was $1.0 \pm 0.1 \mathrm{~mm}^{2}$ for the control muscles and $1.1 \pm 0.1$ $\mathrm{mm}^{2}$ for the myopathic muscles. There were no significant differences between the control and myopathic muscles with regard to any of these parameters. Muscles were placed in baths containing the same physiological salt solution and stretched to the length at which maximal isometric force developed, while being stimulated to contract at $0.33 \mathrm{~Hz}$ with threshold voltage delivered via a punctate electrode located at the base.

A subset of the 32 control and 26 myopathic muscles ( $n=17$ control; $n=17$ myopathic) was macroinjected with the bioluminescent $\mathrm{Ca}^{2+}$ indicator aequorin, as described elsewhere (7). At least one muscle from every heart was loaded with aequorin and the remainder were used for tension analysis only. Light signals were recorded with a photomultiplier tube (9635QA Thorn-EMI, Gencom, Inc., Fairfield, NJ) using a light-collecting apparatus with a design extensively described previously (8). It was usually necessary to average successive signals (from 10 to 100 depending on light intensity $\left[\mathrm{L}_{\max }\right]$ ) to obtain a satisfactory signal-to-noise ratio. Physiological responses (both tension and light) were allowed to reach steady state before signal averaging was performed. The tension and light responses and the stimulus artifact were simultaneously recorded, both on magnetic tape and on strip chart recording paper. The light signal was measured in nanoamperes of anode current and filtered with a time constant of $10 \mathrm{~ms}$. Specific details of the use of aequorin as an indicator of $\left[\mathrm{Ca}^{2+}\right]_{\mathrm{i}}$ and the equipment and methodology required can be found in Blinks (8) and Mackinnon et al. (9).

When $\left[\mathrm{Ca}^{2+}\right]_{\text {o }}$ curves were performed, phosphate was removed from the physiological salt solution to prevent precipitation. Cumulative concentration-response curves to milrinone were performed. To stimulate cAMP production in the control and myopathic muscles, forskolin was added slowly until a slight (i.e., $<10 \%$ of basal values) increase in tension was produced. This occurred at a mean forskolin concentration of $1.12 \pm 0.13 \times 10^{-7} \mathrm{M}$ in the control and $3.5 \pm 0.58$ $\times 10^{-7} \mathrm{M}$ in the myopathic muscles. The milrinone concentrationresponse curve was then repeated in the presence of forskolin.

We have previously reported that, in some experiments, after exposure of aequorin-loaded muscles to high concentrations of certain drugs, an increase in resting luminescence occurred that may have been due to cellular injury (9). Because of this, we dedicated a subset of the aequorin-loaded muscles ( $n=8$ control; $n=9$ myopathic) to quantitation by the method of fractional luminescence in $\left[\mathrm{Ca}^{2+}\right]_{0}=2.5 \mathrm{mM}$ $(10,11)$. To convert our resting and peak $($ at $0.33 \mathrm{~Hz})$ light $(\mathrm{L})$ values to $\left[\mathrm{Ca}^{2+}\right]_{i}$, we estimated the $\mathrm{L}_{\max }$ that would be recorded under the conditions of the experiment if all of the aequorin were instantly exposed to a saturating concentration of $\mathrm{Ca}^{2+} . \mathrm{L}_{\max }$ was determined by lysing the cell membranes with a solution containing $5 \%$ Triton X-100 (Sigma Chemical Co., St. Louis, MO) in $50 \mathrm{mM} \mathrm{CaCl}_{2}$ at $30^{\circ} \mathrm{C}$. Exposure of the aequorin-loaded muscles to this solution resulted in contracture and a burst of light emission. After subtracting the contribution of background light, the integral of the area encompassed by the light signal during exposure to Triton $\mathrm{X}-100$ was multiplied by the rate constant for aequorin consumption in the presence of saturating $\left[\mathrm{Ca}^{2+}\right], 2.11 / \mathrm{s}$, in order to calculate $\mathrm{L}_{\max }$. Determination of the rate constant was performed at $30^{\circ} \mathrm{C}$ after preincubation with $1 \mathrm{mM} \mathrm{Mg}^{2+}$. The ratio of $\mathrm{L} / \mathrm{L}_{\max }$ was converted to a quantitative $\mathrm{Ca}^{2+}$ concentration by using a calibration curve determined in vitro. The in vitro calibration curve used for estimation of $\left[\mathrm{Ca}^{2+}\right]_{i}$ was determined in EDTAbuffered solutions containing $150 \mathrm{mM} \mathrm{K}^{+}$and $1 \mathrm{mM} \mathrm{Mg}^{2+}$ adjusted to pH 7.1 with $3-(N$-morpholino)propanesulfonic acid [MOPS] for pCa $\geq 5.0$ or with $\mathrm{Ca}^{2+}$ dilutions containing $150 \mathrm{mM} \mathrm{KCl}$ and $1 \mathrm{mM} \mathrm{MgCl}$ adjusted to $\mathrm{pH} 7.1$ with $5 \mathrm{mM}$ piperazine- $N, N^{\prime}$-bis(2-ethanesulfonic acid) [PIPES] for $\mathrm{pCa}<4.5$. For more specific details of the calibration procedure, readers should consult Kihara et al. (10).

Aequorin was purchased from the laboratory of Dr. J. R. Blinks, Rochester, MN. Triton X-100 was used for detergent lysis. Milrinone was a generous gift of Sterling-Winthrop, Inc. (Rensselaer, NY), and forskolin was purchased from CalBiochem (San Diego, CA).

Data were compared using unpaired or paired (when appropriate) Student's $t$ tests. Statistical significance was set at $P<0.05$.

\section{Results}

Table I reports the $\mathrm{LV}$ and $\mathrm{RV}$ hemodynamics and mass under control conditions and after the development of dilated cardiomyopathy. Heart rate was increased in the myopathic dogs, while mean arterial blood pressure was decreased. In addition, the LV ejection fraction was depressed in the myopathic dogs. Both LV and RV end-diastolic pressures were significantly elevated in dogs with cardiomyopathy compared with control. In addition, both $\mathrm{LV}$ and $\mathrm{RV} \mathrm{d} P / \mathrm{d} t$ were significantly depressed,

Table I. Indexes of Biventricular Diastolic and Systolic Dysfunction and Pathology in Control and Myopathic Dogs

\begin{tabular}{|c|c|c|}
\hline & Control & Heart failure \\
\hline \multicolumn{3}{|l|}{ LV function } \\
\hline LV systolic pressure $(\mathrm{mmHg})$ & $120 \pm 4$ & $106 \pm 2 *$ \\
\hline $\mathrm{LV}$ end-diastolic pressure $(\mathrm{mmHg})$ & $7 \pm 1$ & $28 \pm 3^{*}$ \\
\hline $\mathrm{LV} \mathrm{d} P / \mathrm{d} t(m m H g / s)$ & $2,965 \pm 143$ & $1,457 \pm 186^{*}$ \\
\hline LV ejection fraction $(\%)$ & $49 \pm 3$ & $29 \pm 3^{*}$ \\
\hline LV end-diastolic volume $(m l)$ & $51 \pm 4$ & $77 \pm 4^{*}$ \\
\hline LV end-systolic volume $(m l)$ & $25 \pm 3$ & $55 \pm 4^{*}$ \\
\hline Heart rate $(b p m)$ & $94 \pm 6$ & $126 \pm 7^{*}$ \\
\hline Mean arterial pressure $(\mathrm{mmHg})$ & $96 \pm 3$ & $84 \pm 3^{*}$ \\
\hline \multicolumn{3}{|l|}{ RV function } \\
\hline $\mathrm{RV}$ systolic pressure $(\mathrm{mmHg})$ & $25 \pm 1$ & $41 \pm 1^{*}$ \\
\hline $\mathrm{RV}$ end-diastolic pressure $(\mathrm{mmHg})$ & $3 \pm 1$ & $10 \pm 1^{*}$ \\
\hline $\mathrm{RV} \mathrm{d} P / \mathrm{d} t(m m H g / s)$ & $949 \pm 24$ & $538 \pm 39^{*}$ \\
\hline \multicolumn{3}{|l|}{ Pathology } \\
\hline Body weight $(k g)$ & $27 \pm 1$ & $27 \pm 1$ \\
\hline LV \& septum $(g)$ & $128 \pm 7$ & $140 \pm 11$ \\
\hline LV \& septum/body weight ( $g / k g)$ & $4.8 \pm 0.1$ & $5.2 \pm 0.3$ \\
\hline $\mathrm{RV}(g)$ & $48 \pm 2$ & $53 \pm 8$ \\
\hline $\mathrm{RV} /$ body weight $(g / k g)$ & $1.8 \pm 0.1$ & $2.0 \pm 0.1$ \\
\hline
\end{tabular}

LV systemic hemodynamics; LV contractile function; and LV, RV, and body weights were obtained from all 15 control and 11 myopathic dogs. In a randomly selected group of five control and five myopathic dogs, RV hemodynamics and contractile function were assessed to confirm biventricular dysfunction. Values are means \pm SEM. ${ }^{*} P$ $<0.05$ vs. control. LV, left ventricle; RV, right ventricle. 
and LV end-systolic and end-diastolic volumes were increased, suggesting biventricular contractile dysfunction. There was a modest but insignificant increase in LV and RV mass. Taken together, these data suggest that there is biventricular dysfunction in this canine model of pacing-induced dilated cardiomyopathy.

Fig. 1 shows the light signals (i.e., $\mathrm{Ca}_{\mathrm{i}}^{2+}$ transients) and isometric twitches recorded with aequorin-loaded cardiac muscle from a sham-operated control and a dilated cardiomyopathic dog. The light signals and twitches were electronically adjusted to equal amplitudes and superimposed to demonstrate the significant prolongation of the time to peak and relaxation of both light and tension in the myopathic myocardium. Table II compares the times to peak tension and light and for decline from peak light and peak tension. The parameters of activation, times to peak tension and light, and relaxation were significantly prolonged in muscles from the myopathic dogs compared with the controls $(P<0.05)$.

Fig. 2 reveals that peak isometric tension development in response to increasing $\left[\mathrm{Ca}^{2+}\right]_{0}$ was depressed in the myopathic muscles; this difference achieved statistical significance at $\left[\mathrm{Ca}^{2+}\right]_{0}$ of $\geq 4 \mathrm{mM}$. At $16 \mathrm{mM}\left[\mathrm{Ca}^{2+}\right]_{0}$, peak tension continued to be depressed in the myopathic dogs, indicating abnormalities in maximal calcium-activated tension generation.

To determine whether the decrease in tension development in the myopathic muscles was due to a decrease in $\mathrm{Ca}_{\mathrm{i}}^{2+}$ availability, we calculated peak and resting $\left[\mathrm{Ca}^{2+}\right]_{\mathrm{i}}$ in $2.5 \mathrm{mM}$ $\left[\mathrm{Ca}^{2+}\right]_{0}$ using the fractional luminescence method (Table III). No differences were found in the resting (diastolic) $\left[\mathrm{Ca}^{2+}\right]_{\mathbf{i}}$ or peak (systolic) $\left[\mathrm{Ca}^{2+}\right]_{i}$, indicating that $\left[\mathrm{Ca}^{2+}\right]_{i}$ homeostasis can be maintained and that a decrease in activator $\left[\mathrm{Ca}^{2+}\right]_{i}$ was not present under these experimental conditions.

To assess the myofilament $\mathrm{Ca}^{2+}$ responsiveness of muscles from this model, $\mathrm{Ca}^{2+}$ concentration-response curves were analyzed with regard to $(a)$ the concentration of $\mathrm{Ca}_{\mathrm{o}}^{2+}$ producing $50 \%$ of maximal tension in each group (i.e., $\left.\mathrm{ED}_{50}\right)$ and $(b)$ the concentration of $\mathrm{Ca}_{\mathrm{o}}^{2+}$ producing maximal tension generation
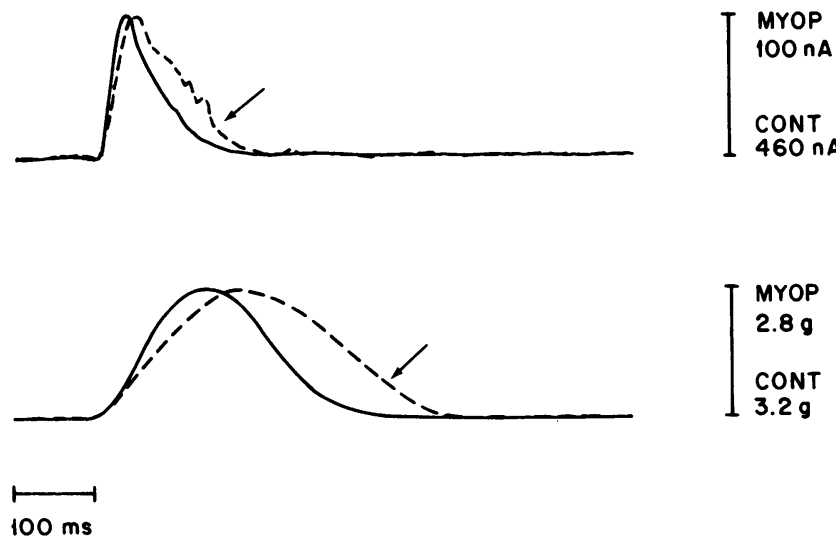

$100 \mathrm{~ms}$

Figure 1. A representative aequorin light signal (top) and tension response (bottom) in a sham-operated control (CONT) and a cardiomyopathic dog (MYOP). The myopathic muscle responses are indicated by the broken lines and the arrows. Light and tension responses were electronically adjusted to equal amplitudes and superimposed in order to compare time courses. Absolute amplitudes of the signals are indicated to the right of each panel. It was necessary to average 20 signals in the control muscle and 21 in the dilated cardiomyopathic muscle to obtain these tracings. Light signals were filtered with a 10ms time constant.
Table II. Characteristics of Light and Tension Responses in Isolated Myocardium from Control and Myopathic Dogs

\begin{tabular}{lcccc}
\hline & TPT & TPL & RT & RL \\
\hline & $m s$ & $m s$ & $m s$ & $m s$ \\
Control & $289 \pm 16$ & $70 \pm 6$ & $301 \pm 23$ & $131 \pm 12$ \\
Myopathic & $338 \pm 13^{*}$ & $93 \pm 5^{*}$ & $384 \pm 21^{*}$ & $234 \pm 39^{*}$
\end{tabular}

Muscles bathed in $2.5 \mathrm{mM}\left[\mathrm{Ca}^{2+}\right]_{0}$ at $30^{\circ} \mathrm{C}$ and stimulated at 3-s intervals with threshold voltage. Values are means \pm SEM. ${ }^{*} P<0.05$ vs. control. TPT, time to peak tension; TPL, time to peak light; RT, time to $90 \%$ decline from peak tension; RL, time to $80 \%$ decline from peak light.

(i.e., $\mathrm{T}_{\max }$ ). In Fig. $3 A$, peak tension responses to increasing $\left[\mathrm{Ca}^{2+}\right]_{0}$ were normalized for differences in maximal force and expressed as a percentage of the maximal response to $\left[\mathrm{Ca}^{2+}\right]_{0}$; there were no differences between the control and myopathic groups at any $\left[\mathrm{Ca}^{2+}\right]_{0}$, including the $\mathrm{ED}_{50}$. The normalized peak light responses were also superimposable (Fig. $3 \mathrm{~B}$ ), suggesting that values for $\left[\mathrm{Ca}^{2+}\right]_{\mathrm{i}}$ at each level of $\mathrm{Ca}_{0}^{2+}$ were similar in both groups. In contrast, the decreased maximal response to $\left[\mathrm{Ca}^{2+}\right]_{0}$ seen before data normalization (Fig. 2) indicates an abnormality in the maximal tension-generating capacity of the myofilaments.

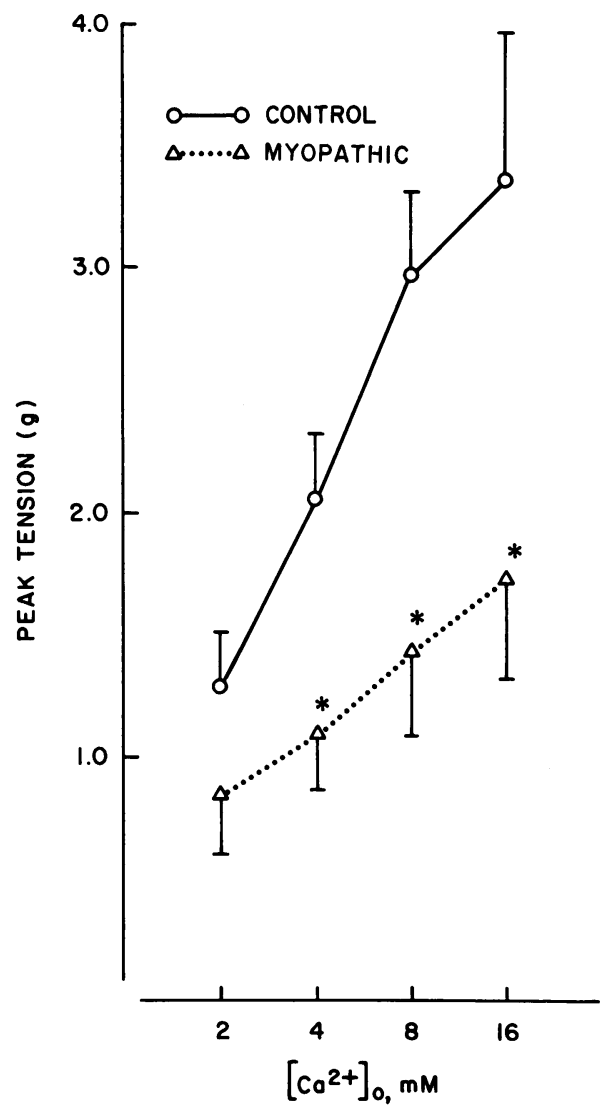

Figure 2. Concentration-response curve to $\left[\mathrm{Ca}^{2+}\right]_{0}$ in muscles from sham-operated control $(0)$ and cardiomyopathic $(\Delta)$ dogs. The peak isometric tension developed at 3-s intervals of stimulation is plotted on the ordinate and the millimolar $\mathrm{Ca}^{2+}$ concentration in the perfusate is plotted on the abscissa. Values are means $\pm \mathrm{SEM} ;{ }^{*} P<0.05$ vs. control. 
Table III. Resting and Peak $\left[\mathrm{Ca}^{2+}\right]_{i}$ in Isolated Myocardium from Control and Myopathic Dogs

\begin{tabular}{lccc}
\hline & $n$ & Resting $\left[\mathrm{Ca}^{2+}\right]_{\mathrm{i}}$ & Peak $\left[\mathrm{Ca}^{2+}\right]_{\mathrm{i}}$ \\
\hline & & $\mu M$ & $\mu M$ \\
Control & 8 & $0.29 \pm 0.05$ & $0.80 \pm 0.13$ \\
Myopathic & 9 & $0.31 \pm 0.02$ & $0.71 \pm .05$
\end{tabular}

$\left[\mathrm{Ca}^{2+}\right]_{\mathrm{i}}$ levels in aequorin-loaded muscles calculated using the method of fractional luminescence. Peak and resting light and light intensity were determined at $30^{\circ} \mathrm{C}$ and $\left[\mathrm{Ca}^{2+}\right]_{0}=2.5 \mathrm{mM}$ in all experiments. Resting values were determined in unstimulated muscle; peak values were determined at stimulation rate of $0.33 \mathrm{~Hz}$. Values are means \pm SEM

Fig. 4 illustrates that the response to the phosphodiesterase inhibitor milrinone was significantly depressed in muscles from dogs with cardiomyopathy. When these same myopathic muscles were pretreated with a minimally effective concentration of forskolin (see Methods for specific concentrations), the response to milrinone was enhanced, as was the response of the control muscles.

\section{Discussion}

This is the first study to directly demonstrate abnormalities in the $\mathrm{Ca}_{\mathrm{i}}^{2+}$ transient and isometric contraction during individual contraction-relaxation cycles in a large animal model of myo- cardial failure. We described three major differences in function of trabeculae between myopathic dogs and the controls: (a) marked prolongation of the $\mathrm{Ca}_{\mathrm{i}}^{2+}$ transient and the corresponding isometric contraction; $(b)$ depression of peak isometric force generation, including a reduction in maximal $\mathrm{Ca}^{2+}-\mathrm{ac}-$ tivated tension at $16 \mathrm{mM}\left[\mathrm{Ca}^{2+}\right]_{0}$; and $(c)$ decreased responsiveness to the phosphodiesterase inhibitor milrinone, a cAMP-dependent positive inotropic agent. The results of the present study are of particular interest since they provide the first example of a heart failure model in which these abnormalities occur in the absence of hypertrophy.

Prolongation of the intracellular $\mathrm{Ca}^{2+}$ transient and isometric contraction. The systolic rise and diastolic decline of myoplasmic $\left[\mathrm{Ca}^{2+}\right]_{i}$ is primarily responsible for regulating cardiac contraction-relaxation cycles; thus, a prolonged duration of the $\mathrm{Ca}_{i}^{2+}$ transient is generally associated with a longer duration of contraction (1). As shown in Fig. 2 and Table II, this correlation appears to apply as well to muscles from this pacing-induced model of failure. Since the duration of the $\mathrm{Ca}_{\mathrm{i}}^{2+}$ transient in mammalian myocardium is largely determined by the rate of $\mathrm{Ca}^{2+}$ resequestration and/or release by the sarcoplasmic reticulum, these results suggest abnormal function of this organelle. The recently described decrease in $\mathrm{Ca}^{2+}$ ATPase activity of sarcoplasmic reticular vesicles from dogs with pacing-induced failure may provide the biochemical basis for these findings (12). An alteration in the expression of the sarcoplasmic reticulum $\mathrm{Ca}^{2+}$ ATPase gene, which correlated with a decrease in the level of mRNA encoding the $\mathrm{Ca}^{2+}$-ATPase of the sarcoplasmic reticulum, has been reported to occur in myopathic human myo-
A. PEAK TENSION

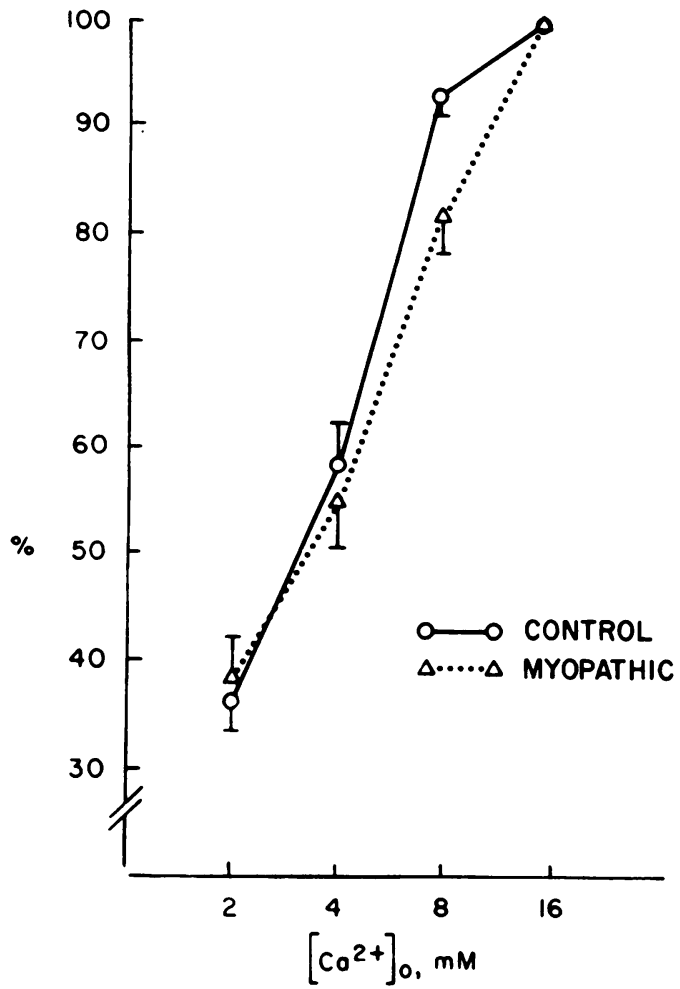

B. PEAK LIGHT

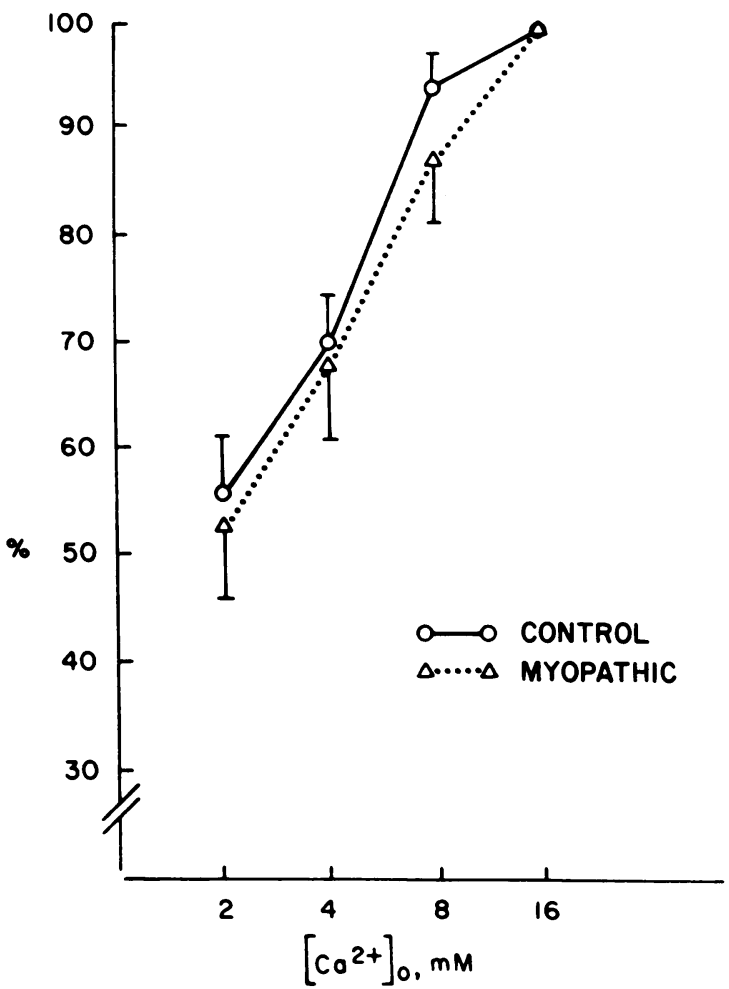

Figure 3. Concentration-response curve to $\left[\mathrm{Ca}^{2+}\right]_{0}$ in aequorin-loaded muscles from sham-operated control $(0)$ and cardiomyopathic $(\triangle)$ dogs. $(A)$ The isometric tension as a percentage of the maximum tension response. $(B)$ The peak light as a percentage of the maximum light response. The percentage of maximal response is plotted on the ordinate and the millimolar $\mathrm{Ca}^{2+}$ concentration in the perfusate is plotted on the abscissa Values are means \pm SEM. 


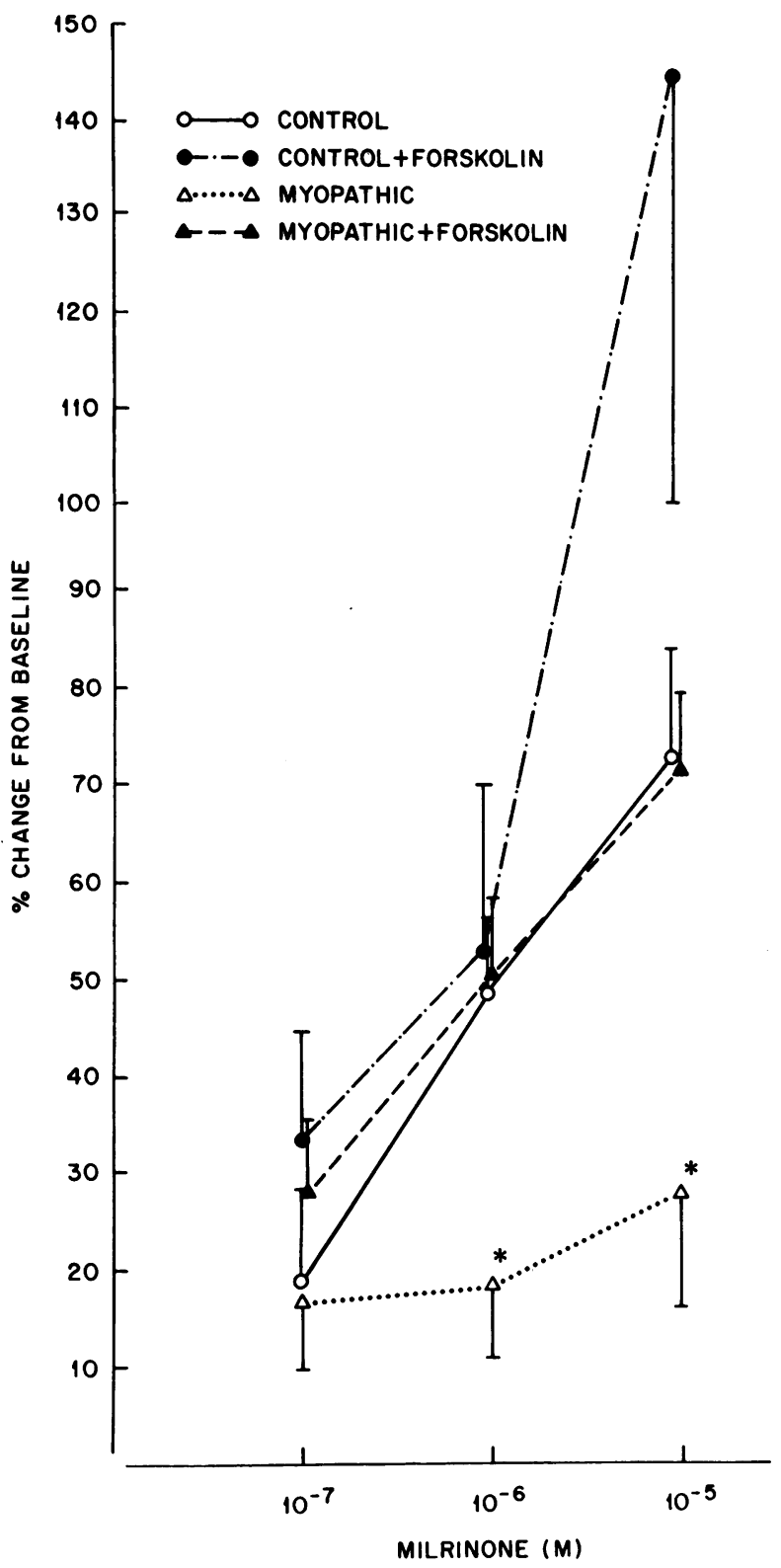

Figure 4. Concentration-response curve to milrinone in muscles from sham-operated control $(0, \bullet)$ and cardiomyopathic $(\Delta, \Delta)$ dogs before $(0, \Delta)$ and after $(\bullet, \Delta)$ the addition of forskolin. The percent change from baseline tension before drug addition is plotted on the ordinate and the concentration of milrinone in the perfusate on the abscissa. Values are means $\pm \mathrm{SEM} ;{ }^{*} P<0.05$ vs. control (preforskolin).

cardium (13). In addition, a decrease in the density or abnormal function of sarcoplasmic reticular $\mathrm{Ca}^{2+}$ pumps has been reported to occur in various models of cardiac hypertrophy and/or failure $(14,15)$. A failure-related decrease in intracellular ATP production may also contribute to the depressed function of the sarcoplasmic reticular $\mathrm{Ca}^{2+}$ pumps $(16,17)$.

Prolongation of the $\mathrm{Ca}_{i}^{2+}$ transient and isometric contraction have been reported in several models of myocardial failure with compensatory hypertrophy. These include genetic hypertension in the spontaneously hypertensive rat, genetic dilated cardiomyopathy in the Syrian hamster, and end-stage heart failure in humans (for review see reference 1). The duration of the $\mathrm{Ca}_{i}^{2+}$ transient also appears to be prolonged in muscle from animal models with significant hypertrophy that are not in clinical heart failure, including RV pressure-overload hypertrophy in ferrets and hypertrophic cardiomyopathy in humans (1). The degree of prolongation of the $\mathrm{Ca}_{i}^{2+}$ transient appears to correlate with the severity of hypertrophy present, at least in humans (18). In this regard, it is of interest to note that the presence of two mechanistically distinct components of the $\mathrm{Ca}_{\mathrm{i}}^{2+}$ transient, $\mathrm{L}_{1}$ and $\mathrm{L}_{2}$, reflecting both sarcoplasmic reticular and sarcolemmal dysfunction, is characteristic of the aequorin signal recorded in human trabeculae from patients with significant hypertrophy, in both the presence and absence of clinical failure (2). In the present series of dogs, we saw evidence of two components in the aequorin light signal in 3 out of 17 aequorin-loaded myopathic muscles studied. Additional studies in canine models with severe hypertrophy will be necessary to determine whether the presence of two components in the canine myocardium correlates with myocyte size, as has been reported in humans.

A shift in the myosin isoenzyme profile, from the fast-cycling $V_{1}$ isoform (which can hydrolyze ATP at a higher rate and thereby support a faster rate of cross-bridge cycling) to the slow-cycling $\mathrm{V}_{3}$ isoform, occurs with cardiac hypertrophy and failure in some species and could contribute to the prolongation of the twitch $(19,20)$. However, the presence of $V_{1}$ in the $R V$ and $L V$ and the shift to $V_{3}$ in response to developmental and pathological stimuli is characteristic of small animals and has not been documented to be of physiological significance in human, pig, or canine myocardium (21-24). Therefore, it is unlikely that the prolongation of the isometric contraction seen in the muscles from the myopathic dogs is due to a shift in myosin isoenzyme composition.

Depression of contractility. In general, the contractile state of the heart can be modulated in two major ways: $(a)$ by altering the availability of activator $\mathrm{Ca}^{2+}$ and $(b)$ by altering the $\mathrm{Ca}^{2+}$ responsiveness of the myofilaments $(25,26)$. $L V$ and $R V \mathrm{~d} P / \mathrm{d} t$ recorded in vivo, and peak isometric tension generation recorded in vitro, were both depressed in the failing groups relative to their controls (Table I, Fig. 2). Of interest, this decrease in contractile performance was most apparent at higher $\left[\mathrm{Ca}^{2+}\right]_{0}$, where contractility should have been enhanced (as it was in the muscles from the control dogs). When $\left[\mathrm{Ca}^{2+}\right]_{0}$ was increased to $\geq 4 \mathrm{mM}$, the myopathic muscles failed to show an increase in contractility relative to the controls and did not achieve control levels of force generation, even with maximal calcium activation at $16 \mathrm{mM}$ (Fig. 2). These results could be explained by a decreased availability of activator $\left[\mathrm{Ca}^{2+}\right]$ owing to abnormal $\mathrm{Ca}^{2+}$ handling by the sarcolemma $(27,28)$ or sarcoplasmic reticulum $(15,16)$, as has been described in other models. However, quantitative determinations of peak and resting calcium indicated no significant differences between the control and myopathic preparations (Table III). Therefore, a more likely explanation of the decreased contractility in the myopathic muscles is that myofilament $\mathrm{Ca}^{2+}$ responsiveness was depressed.

Myofilament $\mathrm{Ca}^{2+}$ responsiveness can be considered in terms of two primary determinants: $(a) \mathrm{Ca}^{2+}$ sensitivity (i.e., the $\mathrm{ED}_{50}$ of the $\mathrm{Ca}^{2+}$-force relationship) and (b) maximal $\mathrm{Ca}^{2+}$ activated tension (i.e., $T_{\max }$ or maximal tension generated in response to $\mathrm{Ca}^{2+}$ activation). Sensitivity corresponds to the classical pharmacological concept of "potency" and $T_{\max }$ to "efficacy." In the present experiments, as shown by Fig. 3, myofilament $\mathrm{Ca}^{2+}$ sensitivity does'not appear to be chạged, 
since the control and myopathic tension and light responses are superimposable when normalized for differences in the maximal responses. In contrast, Fig. 2 shows that maximal $\mathrm{Ca}^{2+}-\mathrm{ac}-$ tivated tension is clearly depressed in the myopathic muscles versus the controls in terms of absolute tension generation. Given the absence of significant changes in the extracellular matrix (6), these results, taken together with an apparently normal $\left[\mathrm{Ca}^{2+}\right]_{\mathrm{i}}$ availability, suggest that decreased myofilament responsiveness, specifically maximal $\mathrm{Ca}^{2+}$-activated, tensiongenerating capacity $\left(\mathrm{T}_{\max }\right)$, is primarily responsible for the depressed contractility in the myopathic muscles.

Intramyocyte factors that can directly affect the force-generating capacity of cardiac muscle include a decrease in myofibrillar ATPase activity, which has been reported in dogs with pacing-induced failure in the absence of changes in myosin ATPase and myosin isoenzyme composition (12). In addition, the dog model of pacing-induced failure has been shown to have abnormal ATP stores available for hydrolysis, as evidenced by decreased whole-cell creatine phosphate/ATP ratios and elevated inorganic phosphate levels at postpacing baseline measured with ${ }^{31} \mathrm{P}$ NMR spectroscopy (29). These types of changes in metabolism may be associated with marked alterations in myofilament $\mathrm{Ca}^{2+}$ responsiveness, as shown by the acute cardiac dysfunction associated with myocardial acidosis (30) and ischemia $(10,31)$. However, if alterations in $\mathrm{pH}$ or inorganic phosphate are present and contributing to the depressed maximal force development in the myopathic muscles, a shift in $\mathrm{Ca}^{2+}$ sensitivity would be expected, and, as shown in Fig. 3, this does not occur.

It is important to note that, besides changes in myofilament $\mathrm{Ca}^{2+}$ responsiveness, it is possible for extracellular factors to contribute to a decrease in the $T_{\max }$ of multicellular preparations like the trabeculae carneae used in these experiments. Extracellular factors include contributions from changes in connective tissue content that could affect the ability of the myocyte to transmit its developed force (32). A variety of extracellular factors may be involved, including increased interstitial collagen, such as has been documented in the LVs of dogs with pacing-induced dilated cardiomyopathy of 5-6-wk duration (32) and in the failing rat (33). However, our preliminary results suggest no increase in connective tissue content in this study, in which dogs were paced for $24 \mathrm{~d}(6)$. The precise combination of factors accounting for a decreased $T_{\max }$ in our model remains to be more fully elucidated.

Although no elevation in resting $\left[\mathrm{Ca}^{2+}\right]_{i}$ was found in these myopathic muscles, it is worth noting that the prolongation of the relaxation of contraction could contribute to contractile dysfunction in vitro under the appropriate circumstances. As we previously reported in human myocardium (34), prolonged calcium transients and twitches, under conditions similar to those of the present experiments, can translate into elevated end-diastolic $\left[\mathrm{Ca}^{2+}\right]_{i}$ and tension, with fusion of $\mathrm{Ca}_{i}^{2+}$ transients and twitches resulting in decreased ventricular compliance at faster stimulation rates. The contribution of diastolic dysfunction to the development of systolic dysfunction in the canine pacing model remains to be further delineated.

Pharmacological profile. In addition to calcium, cAMP is another important second messenger that modulates excitation-contraction in the heart by a variety of cAMP-dependent protein kinases; abnormalities in cAMP production have been implicated in myopathic human myocardium $(4,35,36)$. We therefore examined the ability of the control and myopathic dog muscles to respond to the cAMP-dependent drug milrinone, a phosphodiesterase inhibitor. If similar amounts of intracellular cAMP are present, the response of both groups of muscles should be, at least qualitatively, similar. In the present series of experiments, there was a substantial, positive inotropic response to the phosphodiesterase inhibitor milrinone in all of the control muscles (Fig. 4); in contrast, milrinone produced only a slight, positive inotropic effect in the myopathic muscles. When cAMP production was directly stimulated before milrinone addition, via direct adenylate cyclase activation with forskolin, tension responses to milrinone in the myopathic muscles were enhanced. This pharmacological profile is similar to that reported in human heart failure, suggesting deficient intracellular levels of cAMP that may reflect an alteration in G-protein regulation of adenylate cyclase activity $(4,37,38)$. G-protein abnormalities have been documented to occur in human and animal models of heart failure (39-41). In addition, a depressed level of cAMP available for the regulation of beat-to-beat contractions under normal physiological conditions could be contributing to the prolonged $\mathrm{Ca}_{i}^{2+}$ transients and isometric contractions, in that the rate of release and reuptake of $\mathrm{Ca}^{2+}$ from the sarcoplasmic reticulum is modulated by cAMP-dependent protein kinases $(1,2,4,35)$.

In summary, muscles isolated from dogs with pacing-induced cardiomyopathy demonstrate a prolongation of the $\mathrm{Ca}_{i}^{2+}$ transient and corresponding isometric contraction; produce less tension in response to increasing $\left[\mathrm{Ca}^{2+}\right]_{0}$ than sham-operated controls, and exhibit a markedly depressed inotropic response to the phosphodiesterase inhibitor milrinone, which can be enhanced by direct adenylate cyclase stimulation. Since similar abnormalities appear to be characteristic of myopathic human myocardium, we propose that this model is a good one in which to further elucidate the subcellular mechanisms by which myocardial failure produces abnormalities in contractile function and $\mathrm{Ca}_{\mathrm{i}}^{2+}$ regulation.

\section{Acknowledgments}

The authors express their appreciation to Jason Kravitz for expert secretarial assistance in the preparation of this manuscript.

This study was supported in part by HL-31117, HL-01611, and HL-38070 from the National Institutes of Health and by a grant-in-aid from the American Heart Association.

\section{References}

1. Perreault, C. L., A. J. Meuse, L. A. Bentivegna, and J. P. Morgan. 1990. Abnormal intracellular calcium handling in acute and chronic heart failure: role in systolic and diastolic dysfunction. Eur. Heart J. 11(Suppl. C):8-21.

2. Gwathmey, J. K., L. Copelas, R. MacKinnon, F. J. Schoen, M. D. Feldman, W. Grossman, and J. P. Morgan. 1987. Abnormal intracellular calcium handling in myocardium from patients with end-stage heart failure. Circ. Res. 61:70-76.

3. Li, Q., B. Biagi, R. Starling, C. Hohl, R. Altshuld, and B. Stokes. 1989. Characteristics of calcium transients and electrophysiology in human ventricular myocytes. Biophys. J. 55:488a. (Abstr.)

4. Feldman, M. D., L. Copelas, J. K. Gwathmey, P. Phillips, S. E. Warren, F. J. Schoen, W. Grossman, and J. P. Morgan. 1987. Deficient production of cyclic AMP: pharmacologic evidence of an important cause of contractile dysfunction in patients with end-stage heart failure. Circulation. 75:331-339.

5. Shannon, R. P., K. Komamura, B. S. Stambler, W. T. Manders, and S. F. Vatner. 1991. Alterations in left ventricular geometry and myocardial contractility in conscious dogs with pacing induced dilated cardiomyopathy. Am. J. Physiol. 260(Heart Circ. Physiol.):H1903-H1911.

6. Komamura, K., R. P. Shannon, A. S. Lader, S. P. Bishop, A. Pasipoularides, and S. F. Vatner. 1990. Diastolic dysfunction in conscious dogs with pacing-induced cardiomyopathy. Circulation. 82(Suppl. III):III-112. (Abstr.) 
7. Kihara, Y., and J. P. Morgan. 1989. A comparative study of three methods for intracellular loading of the calcium indicator aequorin in ferret papillary muscles. Biochem. Biophys. Res. Commun. 162:402-407.

8. Blinks, J. R. 1982. The use of photoproteins as calcium indicators in cellular physiology. In Techniques in Cellular Physiology, Part III. B. F. Baker, editor. Elsevier/North-Holland Scientific Publisher, Ltd., Limerick, Ireland. 126/1-126/ 38.

9. MacKinnon, R., J. K. Gwathmey, P. D. Allen, G. M. Briggs, and J. P. Morgan. 1988. Modulation by thyroid state of intracellular calcium and contractility in ferret ventricular muscle. Circ. Res. 63:1080-1089.

10. Kihara, Y., W. Grossman, and J. P. Morgan. 1989. Direct measurement of changes in intracellular calcium transients during hypoxia, ischemia and reperfusion of the intact mammalian heart. Circ. Res. 65:1029-1044.

11. Allen, D. G., and J. R. Blinks. 1978. Calcium transients in aequorin injected frog cardiac muscle. Nature (Lond.). 273:509-513.

12. O'Brien, P. J., C. D. Ianuzzo, G. W. Moe, T. P. Stopps, and P. W. Armstrong. 1989. Rapid ventricular pacing of dogs to heart failure: biochemical and physiological studies. Can. J. Physiol. Pharmacol. 68:34-39.

13. Mercadier, J. J., A. M. Lompre, P. Duc, K. R. Boheler, J. B. Fraysse, C. Wisnewsky, P. D. Allen, M. Komajda, and K. Schwartz. 1990. Altered sarcoplasmic reticulum $\mathrm{Ca}^{2+}$-ATPase gene expression in the human ventricle during endstage heart failure. J. Clin. Invest. 85:305-309.

14. De La Bastie, D., D. Levitsky, L. Rappaport, J. J. Mercadier, F. Marotte, C. Wisnewsky, V. Brovkovich, K. Schwartz, and A. M. Lompre. 1990. Function of the sarcoplasmic reticulum and expression of its $\mathrm{Ca}^{2+}$-ATPase gene in pressure overload-induced cardiac hypertrophy in the rat. Circ. Res. 66:554-564.

15. Panagia, V., S. L. Lee, A. Singh, G. N. Pierce, G. Jasmin, and N. S. Dhalla 1986. Impairment of mitochondrial and sarcoplasmic reticular functions during the development of heart failure in cardiomyopathic (UM-X7.1) hamsters. Can. J. Cardiol. 2:236-247.

16. Katz, A. M. 1989. Energy requirements of contraction and relaxation: implications for inotropic stimulation of the failing heart. Basic Res. Cardiol. 84(Suppl. 1):47-53.

17. Ingwall, J. S., D. E. Atkinson, K. Clarke, and J. K. Fetters. 1990. Energetic correlates of the cardiac failure: changes in the creatine kinase system in the failing myocardium. Eur. Heart J. 11(Suppl. B):108-115.

18. Bentivegna, L. A., B. J. Ransil, W. Grossman, J. K. Gwathmey, and J. P. Morgan. 1989. Cardiac hypertrophy and abnormal calcium handling in human myocardium. Circulation. 80(Suppl. II):617. (Abstr.)

19. Alpert, N. R., and L. A. Mulieri. 1986. Functional consequence of altered cardiac myosin isoenzymes. Med. Sci. Sports Exercise. 18:309-313.

20. Bing, O. H. L., W. W. Brooks, C. H. Conrad, S. Sen, C. L. Perreault, and J. P. Morgan. 1991. Intracellular calcium transients in myocardium from spontaneously hypertensive rats during the transition to heart failure. Circ. Res. 68:1390-1400.

21. Rouleau, J.-L., P. Paradis, H. Shenasa, and C. Juneau. 1986. Faster time to peak tension and velocity of shortening in right versus left ventricular trabeculae and papillary muscles of dogs. Circ. Res. 56:556-561.

22. Mercadier, J. J., P. Bouveret, L. Gorza, S. Schiceffino, W. A. Clark, R. Lak, B. Swynghedauw, and K. Schwartz. 1983. Myosin isoenzymes in norma and hypertrophied human ventricular myocardium. Circ. Res. 53:52-62.

23. Wisenbaugh, T., P. Allen, G. Cooper IV, H. Holzgrefe, G. Beller, and B. Carabello. 1983. Contractile function, myosin ATPase activity and isoenzymes in the hypertrophied pig left ventricle after a chronic progressive pressure overload. Circ. Res. 53:332-341.
24. Morano, I., H. Arndt, C. Gärtner, and J. C. Rüegg. 1988. Skinned fibers of human atrium and ventricle: myosin isoenzymes and contractility. Circ. Res. 62:632-639.

25. Perreault, C. L., O. H. L. Bing, W. W. Brooks, B. J. Ransil, and J. P. Morgan. 1990. Differential effects of hypertrophy and failure on right versus left ventricular calcium activation. Circ. Res. 67:707-712.

26. Blinks, J. R., and M. Endoh. 1986. Myofibrillar responsiveness to $\mathrm{Ca}^{++}$as an inotropic mechanism. Circulation. 73:85-98.

27. Dhalla, N. S., and D. Zhao. 1986. Possible role of sarcolemmal Ca ${ }^{2+} / \mathrm{Mg}^{2+}$ ATPase in heart function. Magnesium Res. 2:161-172.

28. Kohmoto, O., K. W. Spitzer, M. A. Movsesian, and W. H. Barry. 1990. Effects of intracellular acidosis of $\left[\mathrm{Ca}^{2+}\right]_{i}$ transients, transsarcolemmal $\mathrm{Ca}^{2+}$ fluxes, and contraction in ventricular myocytes. Circ. Res. 66:622-632.

29. Henry, T. D., J. Zhang, M. Yoshiyama, V. Chepuri, K. Ugurbil, A. H. L. From, and R. J. Bache. 1991. Myocardial bioenergetic abnormalities in the rapid ventricular pacing model of congestive heart failure. J. Am. Coll. Cardiol. 17(Part 2):295a. (Abstr.)

30. Poole-Wilson, P. A. 1989. Regulation of intracellular pH in the myocardium; relevance to pathology. Mol. Cell. Biochem. 89:151-155.

31. Allen, D. G., J. A. Lee, and G. L. Smith. 1989. The consequences of simulated ischemia on intracellular $\mathrm{Ca}^{2+}$ and tension in isolated ferret ventricular muscles. J. Physiol. (Lond.). 410:297-323.

32. Weber, K. T., R. Pick, M. A. Silver, G. W. Moe, J. S. Janicki, I. H. Zucker, and P. W. Armstrong. 1990. Fibrillar collagen and remodeling of dilated canine left ventricle. Circulation. 82:1387-1401.

33. Conrad, C. H., W. W. Brooks, S. Sen, K. G. Robinson, and O. H. L. Bing. 1990. Increased collagen content may contribute to increased myocardial stiffness and heart failure in the spontaneously hypertensive rat. J. Am. Coll. Cardiol. 15:48a. (Abstr.)

34. Gwathmey, J. K., M. T. Slawsky, R. J. Hajiar, G. M. Briggs, and J. P. Morgan. 1990. Role of intracellular calcium handling in force-interval relationships of human ventricular myocardium. J. Clin. Invest. 85:1599-1613.

35. Katz, A. M. 1983. Cyclic adenosine monophosphate effects on the myocardium: a man who blows hot and cold with one breath. J. Am. Coll. Cardiol. 2:143-149.

36. Opie, L. H. 1982. Role of cyclic nucleotides in heart metabolism. Cardiovasc. Res. 16:483-507.

37. Nabauer, M., M. Bohm, L. Brown, F. Diet, M. N. Eichhorn, B. Kemkes, B. Pieske, and E. Erdmann. 1988. Positive inotropic effects in isolated ventricular myocardium from non-failing and terminally failing human hearts. Eur. J. Clin. Invest. 18:600-606.

38. Erdmann, E., and M. Bohm. 1989. Positive inotropic stimulation in the normal and insufficient human myocardium. Basic Res. Cardiol. 84(Suppl. 1):125-133.

39. Longabough, J. P., D. E. Vatner, S. F. Vatner, and C. J. Homcy. 1988. Decreased stimulatory GTP binding protein in dogs with pressure-overload left ventricular failure. J. Clin. Invest. 81:420-424.

40. Bohm, M., P. Gierschik, K. H. Jakobs, B. Pieske, M. Ungerer, and E. Erdmann. 1990. Increase in $\mathrm{G}_{\mathrm{i}}$ alpha in human hearts with dilated but not ischemic cardiomyopathy. Circulation. 82:1249-1265.

41. Feldman, A. M., R. G. Tena, P. D. Kessler, H. F. Weisman, S. P. Schulman, R. S. Blumenthal, D. G. Jackson, and C. Van Dop. 1990. Diminished beta-adrenergic receptor responsiveness and cardiac dilitation in the hearts of myopathic Syrian hamsters (BIO 53, 58) are associated with a functional abnormality of the $\mathrm{G}$ protein. Circulation. 81:1341-1352. 